\title{
Carvacrol Alleviates Prostate Cancer Cell Proliferation, Migration, and Invasion through Regulation of PI3K/Akt and MAPK Signaling Pathways
}

\author{
Yun Luo, ${ }^{1}$ Jie-Ying Wu, ${ }^{1}$ Min-Hua Lu, ${ }^{1}$ Zhi Shi, ${ }^{2}$ Ning $\mathrm{Na}^{3}$ and Jin-Ming $\mathrm{Di}^{1}$ \\ ${ }^{1}$ Department of Urology, The 3rd Affiliated Hospital of Sun Yat-Sen University, Guangzhou, Guangdong 510630, China \\ ${ }^{2}$ Department of Cell Biology \& Institute of Biomedicine, National Engineering Research Center of Genetic Medicine, \\ Guangdong Provincial Key Laboratory of Bioengineering Medicine, College of Life Science and Technology, Jinan University, \\ Guangzhou, Guangdong 510632, China \\ ${ }^{3}$ Department of Kidney Transplantation, The 3rd Affiliated Hospital of Sun Yat-Sen University, Guangzhou, Guangdong 510630, China
}

Correspondence should be addressed to Ning Na; 37361866@qq.com and Jin-Ming Di; dijinm@mail.sysu.edu.cn

Received 21 May 2016; Revised 21 July 2016; Accepted 14 August 2016

Academic Editor: Domenico D’Arca

Copyright (C) 2016 Yun Luo et al. This is an open access article distributed under the Creative Commons Attribution License, which permits unrestricted use, distribution, and reproduction in any medium, provided the original work is properly cited.

TRPM7 is a potential therapeutic target for treatment of prostate cancer. In this study, we investigated the effects of nonselective TRPM7 inhibitor carvacrol on cell proliferation, migration, and invasion of prostate cancer PC-3 and DU145 cells. Our results showed that carvacrol blocked TRPM7-like currents in PC-3 and DU145 cells and reduced their proliferation, migration, and invasion. Moreover, carvacrol treatment significantly decreased MMP-2, p-Akt, and p-ERK1/2 protein expression and inhibited F-actin reorganization. Furthermore, consistently, TRPM7 knockdown reduced prostate cancer cell proliferation, migration, and invasion as well. Our study suggests that carvacrol may have therapeutic potential for the treatment of prostate cancer through its inhibition of TRPM7 channels and suppression of PI3K/Akt and MAPK signaling pathways.

\section{Introduction}

Prostate cancer ( $\mathrm{PCa}$ ) is the second leading cause of cancerrelated death in men [1-3]. Although multiple treatment options are available, it is currently lack of effective therapies for the treatment of androgen-independent prostate cancer which often arises after hormonal deprivation or ablation therapy [4].

Transient receptor potential melastatin-like 7 channel (TRPM7) is a member of melastatin-like transient receptor potential (TRPM) subfamilies, widely expressed in mammalian cells [5]. It is permeable to $\mathrm{Ca}^{2+}$ and $\mathrm{Mg}^{2+}$ and other divalent cations and has an alpha-kinase domain [6]. It is found that TRPM7 is highly expressed in a number of human cancer tissues and cell lines to regulate cell proliferation, migration, and invasion, such as glioblastoma [7], ovarian cancer [8], and breast cancer [9]. Increasing $\mathrm{Ca}^{2+}$ and $\mathrm{Mg}^{2+}$ influx promotes the proliferation of prostate cancer cells through activating TRPM7 [10]. Moreover, cholesterol activates TRPM7 and thus increases $\mathrm{Ca}^{2+}$ entry, regulating proliferation, migration, and viability of human prostate cells [11]. Inhibition of TRPM7 enhances TNF-related apoptosis inducing-ligand- (TRAIL-) induced apoptosis in PC-3 cells [12], indicating that TRPM7 contributes to the pathogenesis of prostate cancer and serves as a potential therapeutic target for prostate cancer [13]. So far, several signaling pathways were reported to be regulated by TRPM7, including signal Transducer and Activator of Transcription 3 (STAT3), Notch, PI3K/Akt, and MAPK signaling pathways [14, 15]. In prostate cancer cells, knockdown TRPM7 by shRNA inhibited cholesterol-induced Akt or ERK phosphorylation [11]. Hence, it suggests that both PI3K/Akt and MAPK signaling pathways are the downstream mechanisms of TRPM7 functions in prostate cancer.

Carvacrol (CAR) is a natural-bioactive monoterpenoid phenol with multiple uses. It is used as flavor agent in 
cosmetic and food products and the most active constituent of thyme EOs extracted from many plants, including fruits, vegetables, spices, and herbs. Carvacrol also exhibits antifungal, antiviral, antitumor, and anti-inflammatory activities [16]. Carvacrol was first reported by Parnas et al. as a nonselective TRPM7 inhibitor [17]. The inhibitory effects of carvacrol on TRPM7 and TRPM7-like currents in HEK293 cells and glioblastoma cell line were further confirmed [7]. However, the pharmacological effects of carvacrol on the proliferation, migration, and invasion of prostate cancer cells have not yet been investigated.

In this study, we compared the TRPM7 protein expression between control prostate cells and PCa cells. We further evaluated the effects of carvacrol on TRPM7-like currents, proliferation, migration, and invasion in PC-3 and DU145 cells and investigated the potential underlying mechanisms involved in these effects.

\section{Materials and Methods}

2.1. Cell Culture and Reagents. Nonneoplastic human prostatic epithelial cells (RWPE-1) using as control prostate cell line as well as prostate cancer cell lines DU145 (HTB81) and PC-3 (CRL1435) were obtained from the American Type Culture Collection (Manassas, VA). PWPE-1 cells were maintained in defined keratinocyte serum-free medium (KSFM) containing $50 \mu \mathrm{g} / \mathrm{mL}$ bovine pituitary extract and $5 \mathrm{ng} / \mathrm{mL}$ EGF (Invitrogen, USA). DU145 and PC-3 cells were cultured in DMEM with 10\% fetal bovine serum, penicillin $(100 \mathrm{U} / \mathrm{mL})$, and streptomycin $(100 \mathrm{ng} / \mathrm{mL})$ and maintained at $37^{\circ} \mathrm{C}$ with $95 \%$ humidified air and $5 \% \mathrm{CO}_{2}$ and passaged as needed. Culture medium was changed twice weekly. Cell culture related materials were purchased from Gibco Life Technologies Corporation (USA). All other reagents used were purchased from Sigma-Aldrich (USA) unless mentioned otherwise.

2.2. RNAi Assay. Lentivirus plasmids were obtained from Addgene (Cambridge, MA) in pLKO.1 cloning vector and contained either nonspecific control shRNA (sh-Control) or shRNA specific for human TRPM7 (GeneBank: AY032950). According to the other study, the sequences for TRPM7 and control shRNA were as follows: GTCTTGCCATGAAATACTC and TGTGCTCCGAACGTGTAGT [18]. ShRNA viruses were packaged and produced following the protocol provided online by Addgene Company (http://www.addgene .org/tools/protocols/plko/). PC-3 cells were infected with either lentiviral-sh-Control or lentiviral-sh-TRPM7 (MOI = 40). Culture medium was changed to the fresh medium $24 \mathrm{~h}$ after infection. TRPM7, p-Akt, and p-ERK1/2 protein expression were determined at $72 \mathrm{~h}$ after infection, and TRPM7like current was determined as well. In the meantime, cells with infection for $72 \mathrm{~h}$ were digested and seeded into the corresponding culture plate to carry out CCK-8 assay, wound healing, and Transwell assay.

2.3. CCK-8 Assay. The viability and proliferation of PC-3 and DU145 cells were examined using CCK-8 kit (Tongren Shanghai Co., China) according to the manufacturer's instructions.
Briefly, cells were seeded on 96-well plates at a density of 0.5 $\times 10^{5}$ cells/well and grown for additional $24 \mathrm{~h}$ prior to the experiment. Cells were treated as indicated concentration of carvacrol and corresponding vehicle for 24,48 , and $72 \mathrm{~h}$. Then CCK-8 solution $(10 \mu \mathrm{L})$ was added to each well and incubated for additional $1 \mathrm{~h}$. Absorbance at $450 \mathrm{~nm}$ was measured using a microplate reader (Syngery H1, Biotek, USA). Cell viability was expressed as a percentage of the vehicle control.

2.4. Colony Formation. Colony formation experiments were carried out according to our previous study $[19,20]$. PC-3 and DU145 cells (300 cells/well) were seeded in 6-well plates overnight and subsequently treated with carvacrol $(500 \mu \mathrm{M})$ for $24 \mathrm{~h}$, and then it was replaced with fresh culture medium without carvacrol. After that, culture medium was changed every 5 days. After 10 days of culture, cells were fixed with $100 \%$ ice-cold Methanol for 10 minutes and stained with $0.5 \%$ crystal violet solution for $10 \mathrm{~min}$, then washed with water, and air-dried. Cell colonies images were captured using a digital camera connected to a phase-contrast Olympus microscope ( $\times 10$ objectives). Colony numbers (containing $>50$ cells) were determined using Image-Pro Plus software. Data were presented as a percentage of vehicle control.

2.5. Wound Healing. Wound healing experiments were carried out according to our previous study [21, 22]. Briefly, cells were seeded in 6 -well plates $\left(5 \times 10^{5} /\right.$ well $)$ and grown to about $80 \%$ confluence, and then the monolayer of cells was scratched with a $200 \mu \mathrm{L}$ pipette tip to create a wound gap and treated with either carvacrol $(500 \mu \mathrm{M})$ or corresponding vehicle control for 24 and $48 \mathrm{~h}$. Cells were allowed to migrate in serum-free medium as indicated time point. Cell images and the scratches were photographed using a phasecontrast Olympus microscope (10x objective). Throughout experiments, the same visual field was used. The gap lengths were measured by Image-Pro Plus software.

2.6. Transwell Assay. Invasion experiments were carried out according to our previous study [14, 23]. BioCoat Matrigel invasion chambers $(8 \mu \mathrm{m}$ polycarbonate Nucleopore filters, Cat. 354480) were used. Briefly, PC-3/DU145 cells were treated with carvacrol $(500 \mu \mathrm{M})$ or equivalent vehicle for $24 \mathrm{~h}$. Then $100 \mu \mathrm{L}$ of cells $\left(2.5 \times 10^{4}\right.$ cells $\left./ \mathrm{mL}\right)$ in FBS-free DMEM was plated in the upper chamber and the lower chamber contained medium with 10\% FBS/DEEM. After incubating for $24 \mathrm{~h}$ at $37^{\circ} \mathrm{C}$ in $5 \% \mathrm{CO}_{2}$, nonmigrated cells in upper chamber were scraped from the upper surface of the membrane using cotton swab. Migrated cells remaining on the bottom surface were fixed with $75 \%$ ethanol and stained with crystal violet $(0.1 \%)$. Finally, images of the invaded cells were photographed and invading cells were counted using Image-Pro Plus software.

2.7. Immunofluorescent Staining. Immunofluorescent staining experiments were carried out according to our previous study $[24,25]$. Cells were fixed with $4 \%$ paraformaldehyde for $30 \mathrm{~min}$ at room temperature (RT) and then permeabilized for $30 \mathrm{~min}$ with $0.1 \%$ Triton $\mathrm{X}-100$ in PBS. Rhodamine 
phalloidin staining was performed following the manufacturer's instructions. Cells were incubated with rhodamine phalloidin (1:50; Molecular Probes, USA) to label F-actin and with DAPI $(1 \mu \mathrm{g} / \mathrm{mL}$, Sigma-Aldrich, USA) to label nucleic acid, for $20 \mathrm{~min}$ at RT. Immunofluorescent images were captured from at least 6 randomly chosen areas using Zeiss confocal microscope.

2.8. Patch Clamp Recording. Patch clamp experiments were carried out according to Sun et al's report [10]. Whole cell currents were recorded using an Axopatch 200B (Axon Instruments, Inc.), with holding potential of $0 \mathrm{mV}, 100 \mathrm{~ms}$ voltage ramps ranging from -100 to $+100 \mathrm{mV}$, and 2-s intervals at $2 \mathrm{kHz}$. pClamp 9.2 software was used for data acquisition and analysis. The bath solution contained $145 \mathrm{~mm}$ $\mathrm{NaCl}, 5 \mathrm{~mm} \mathrm{CsCl}, 1 \mathrm{~mm} \mathrm{MgCl}, 1 \mathrm{~mm} \mathrm{CaCl}_{2}, 10 \mathrm{~mm}$ Hepes, $10 \mathrm{~mm}$ glucose, and $\mathrm{pH} 7.4(\mathrm{NaOH})$. Patch pipette resistance was between 3-5 megaohms after filling with pipette solution containing $150 \mathrm{~mm}$ cesium methane sulfonate, $8 \mathrm{~mm} \mathrm{NaCl}$, $10 \mathrm{~mm}$ Hepes, $10 \mathrm{~mm}$ EGTA, and pH 7.2 (CsOH). All recordings were carried out at RT.

2.9. Western Blot. Western blotting experiments were carried out according to our previous study $[26,27]$. Briefly, cells were lysed in RIPA buffer (1\% NP-40, 0.5\% sodium deoxycholate, $0.1 \%$ SDS, $10 \mathrm{ng} / \mathrm{mL}$ PMSF, $0.03 \%$ aprotinin, and $1 \mu \mathrm{M}$ sodium orthovanadate) on ice for $30 \mathrm{~min}$. Protein concentration of samples was measured with the bicinchoninic acid (BCA) assay method. Proteins were separated on 8-12\% SDS-PAGE gels and transferred to nitrocellulose membrane (Millipore, USA). Membranes were blocked with 5\% BSA in TBS with $0.1 \%$ tween-20 and incubated with primary antibodies as follows: anti-TRPM7 (1:1000, Abcam, \#ab85016, USA), anti-pAkt-Ser473 (1:1000, Cell Signaling Technology, \#4060, Inc., USA), anti-Akt (1:1000, Cell Signaling Technology, \#2920 Inc., USA), phospho-p44/42 MAPK (p-ERK1/2, 1:1000, Cell Signaling Technology, \#8544, Inc., USA), anti-ERK1/2 (1:1000, Cell Signaling Technology, \#4696, Inc., USA), and anti- $\beta$-actin $(1: 1000$, Cell Signaling Technology, \#3700, Inc., USA) antibodies followed by incubation with corresponding horseradish peroxidase-conjugated secondary antibodies were used against each primary antibody. Bands were developed with a chemiluminescence reagent system (Beyotime, China).

2.10. Statistical Analysis. Data are presented as means \pm SEM. Two-way unpaired Student's $t$-test was used to compare the statistical significance between two groups, and ANOVA with subsequent Newman-Keuls test was used for multiple comparisons. $p<0.05$ was considered statistically significant for all tests.

\section{Results}

3.1. Carvacrol Reduces TRPM7-Like Currents in PCa Cells. We determined TRPM7 protein expression in RWPE-1, PC-3, and DU145 cells. As shown in Figure 1(a), western blotting results showed that TRPM7 protein expressed in these cells was higher in prostate cancer cell lines (PC-3 and
DU145) than that in normal control prostate cell, RWPE1. Carvacrol treatment for $24 \mathrm{~h}$ did not significantly affect TRPM7 expression of PC-3 and DU145 (Figure 1(b)). Next, we employed whole cell path-clamp to record TRPM7-like currents in PC-3 and DU145 cells. The current density in PC-3 and DU145 at $+100 \mathrm{mV}$ was $24.5 \pm 2.3 \mathrm{pA} / \mathrm{pF}$ (Figures $1(\mathrm{c}), 1(\mathrm{~d})$, and $1(\mathrm{e})$ ) and $35.9 \pm 4.2 \mathrm{pA} / \mathrm{pF}$ (Figures $1(\mathrm{f})$ and $1(\mathrm{~g}))$. Carvacrol $(500 \mu \mathrm{M})$ significantly reduced TRPM7-like currents (at $+100 \mathrm{mV}$ ) in PC-3 and DU145 cell by $~ 52 \%$ and $45 \%(p<0.05, n=6)$, respectively. Besides, carvacrol $(500 \mu \mathrm{M})$ significantly reduced the currents at $-100 \mathrm{mV}$ in PC-3 and DU145 cells (Figures 1(e) and 1(g)).

3.2. Carvacrol Inhibits PC-3 and DU145 Cell Proliferation. Then, we evaluated the effects of carvacrol on the proliferation of PCa cells. As shown in Figure 2(a), CCK-8 assay results showed that carvacrol reduced the viability of PC-3 and DU145 cells in a dose-dependent manner, with $\mathrm{IC}_{50}$ of $498.3 \pm 12.2 \mu \mathrm{M}$ and $430.6 \pm 21.9 \mu \mathrm{M}$, respectively. As shown in Figure 2(b) (left panel), the proliferation of PC-3 cells in the control group increased with time (128.9 $\pm 3.0 \%, 230.1 \pm 8.4 \%$, and $320.1 \pm 5.7 \%$ at 24,48 , and 72 hours). When cells were treated with 250,500 , and $750 \mu \mathrm{M}$ carvacrol, the rate of cell proliferation significantly decreased at 24,48 , and 72 hours $(p<0.05, n=6)$. Meanwhile, we observed the similar effects of carvacrol on cell proliferation of DU145 (Figure 2(b), right panel). We further determined the antiproliferation effects of carvacrol using colony formation experiments. As shown in Figures 2(c) and 2(d), $500 \mu \mathrm{M}$ carvacrol significantly reduced colony numbers of PC-3 and DU145 by $56.2 \pm 8.6 \%$ and $49.8 \pm 6.7 \%$, respectively $(p<0.05, n=6)$.

3.3. Carvacrol Reduces PCa Cell Migration. Wound healing assay was carried out to detect cell migration. As shown in Figures 3(a) and 3(b), after treatment of $24 \mathrm{~h}$, wound closures of PC-3 and DU145 in control group were $56.4 \pm 8.5$ and $38.7 \pm$ 5.9 , respectively. And after treatment of $48 \mathrm{~h}$, wound closure of vehicle control in PC-3 and DU145 cells increased to 83.9 \pm $4.2 \%$ and $92.5 \pm 7.1 \%$, respectively. Carvacrol significantly inhibited cell wound healing of PC-3 and DU145 cells $(p<$ $0.05, n=6$ ), as the wound closure of PC-3 and DU145 cells in carvacrol treatment group was $31.8 \pm 9.2$ and $21.6 \pm 4.1$ at $24 \mathrm{~h}$ and $42.4 \pm 8.6 \%$ and $35.6 \pm 7.9 \%$ at $48 \mathrm{~h}$, respectively. Thus, compared with vehicle control, carvacrol $(500 \mu \mathrm{M})$ significantly reduced PC-3 and DU145 cell migration.

As cell migration is related to reorganization of the actin cytoskeleton, we also measured the cytoskeletal actin organization by staining F-actin with phalloidin in PC-3 cells and DU145 cells. As shown in Figures $3\left(\mathrm{a}^{\prime}\right)$ and $3\left(\mathrm{~b}^{\prime}\right)$, F-actin was condensed at the leading edge within structures resembling fans or protrusions in vehicle group. After treatment with carvacrol, less F-actin was condensed in dot-like structures at the margins of the cells, compared to vehicle control cells. The data suggest that inhibition of cell migration by carvacrol might be related to its prevention of F-actin reorganization.

3.4. Carvacrol Inhibits PCa Cell Invasion. We further detected whether carvacrol could inhibit PCa cell invasion using Transwell invasion assay. As shown in Figures 4(a) and 4(b), 


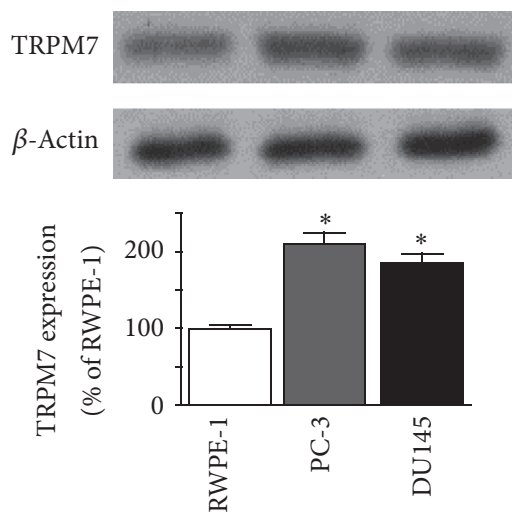

(a)

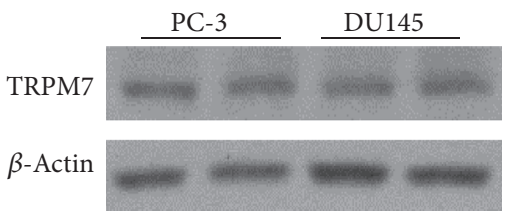

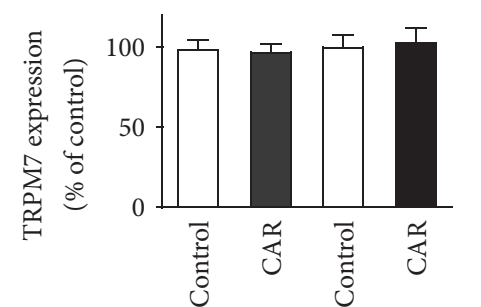

(b)

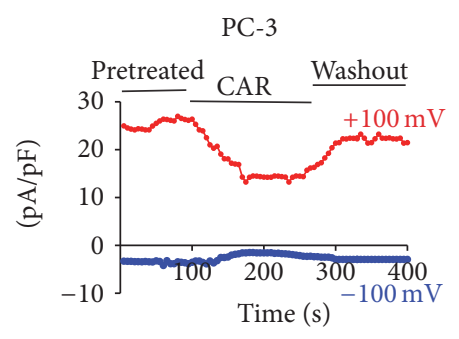

(c)

PC-3

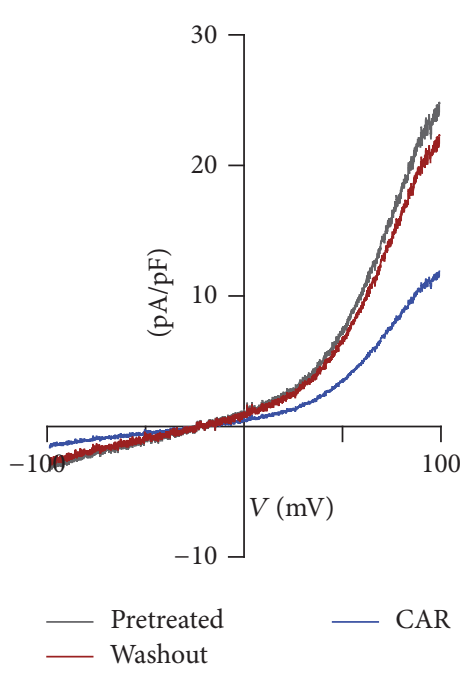

(d)

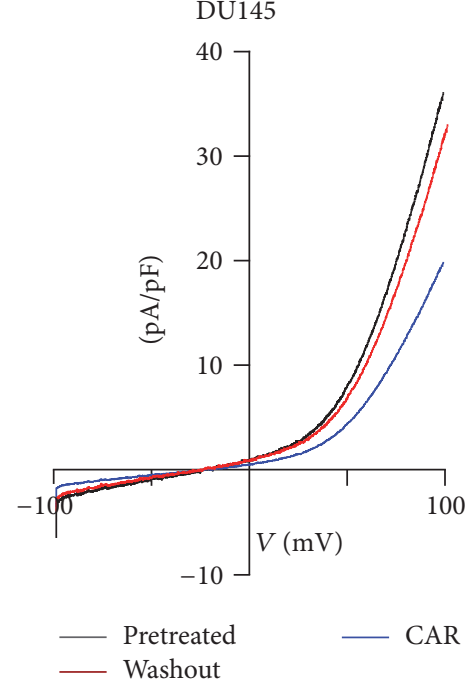

(f)

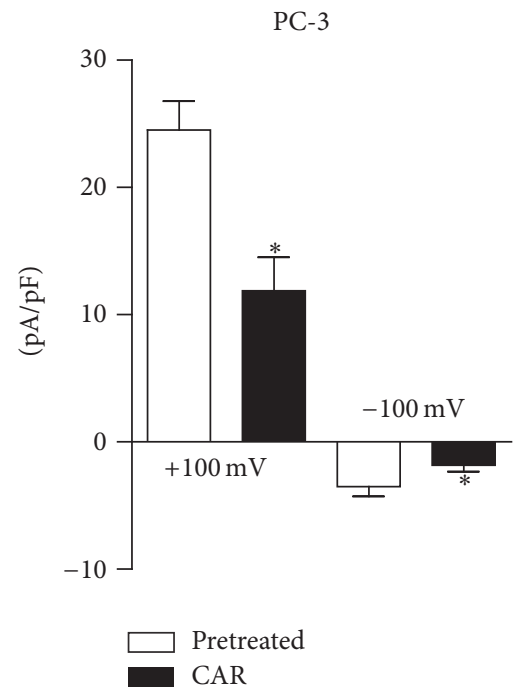

(e)

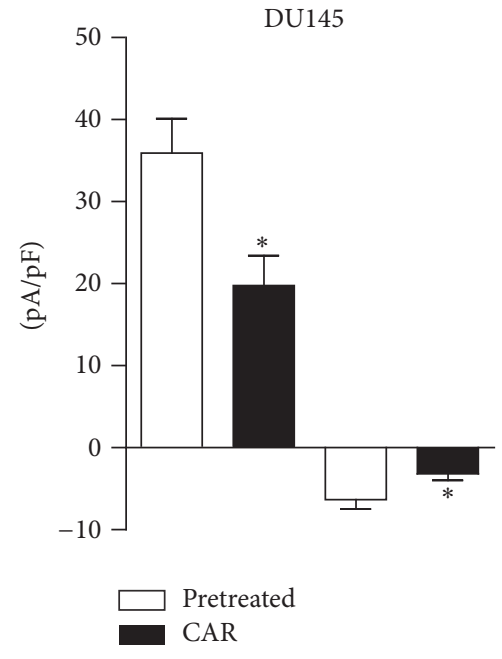

(g)

FIgURE 1: Carvacrol (CAR) inhibited TRPM7-like currents in PCa cells. (a) TRPM7 protein expression detected by western blotting $\left({ }^{*} p<0.05\right.$ versus RWPE-1 cells, $n=6$ ). (b) PC-3 and DU145 cells were treated with carvacrol ( $500 \mu \mathrm{M})$ for $24 \mathrm{~h}$. TRPM7 protein expression was detected by western blot. (c) Representative current traces of inward and outward currents at $+100 \mathrm{mV}$ and $-100 \mathrm{mV}(n=3)$. The current traces were started to record when the TRPM7-like currents reached a platform after the finish of the whole cell configuration. Both inward and outward currents were inhibited by carvacrol $(500 \mu \mathrm{M})$, and they recovered after carvacrol washout. (d) Representative current-voltage trace of TRPM7-like current in PC-3 cells treated with either vehicle control (pretreated) or carvacrol (500 $\mu \mathrm{M})$. (e) Statistical analysis of current density at $+100 \mathrm{mV}$ and $-100 \mathrm{mV}$ in PC-3 cells $\left({ }^{*} p<0.05\right.$ versus pretreated, $\left.n=6\right)$. (f) Representative current-voltage trace of TRPM7-like current in DU145 cells treated with either vehicle control or carvacrol $(500 \mu \mathrm{M})$. (g) Statistical analysis of current density at $+100 \mathrm{mV}$ and $-100 \mathrm{mV}$ in DU145 cells $\left({ }^{*} p<0.05\right.$ versus pretreated, $\left.n=6\right)$. 


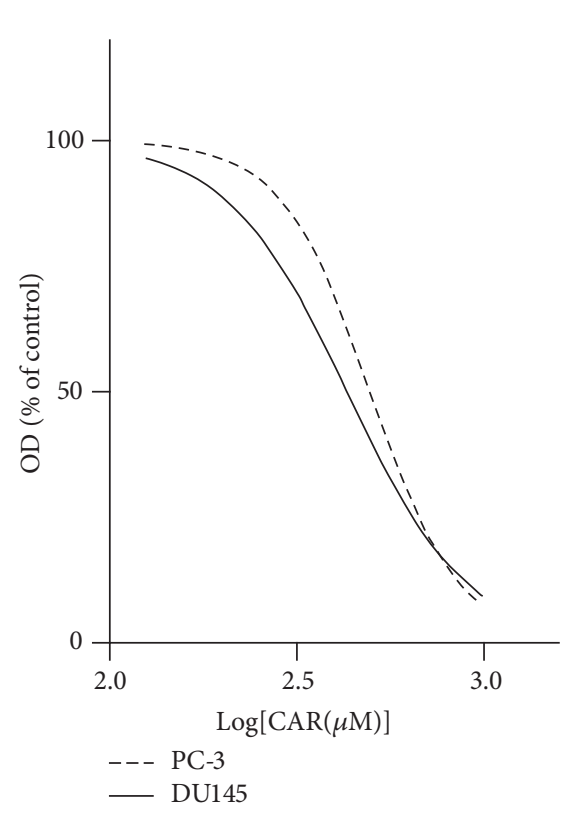

(a)

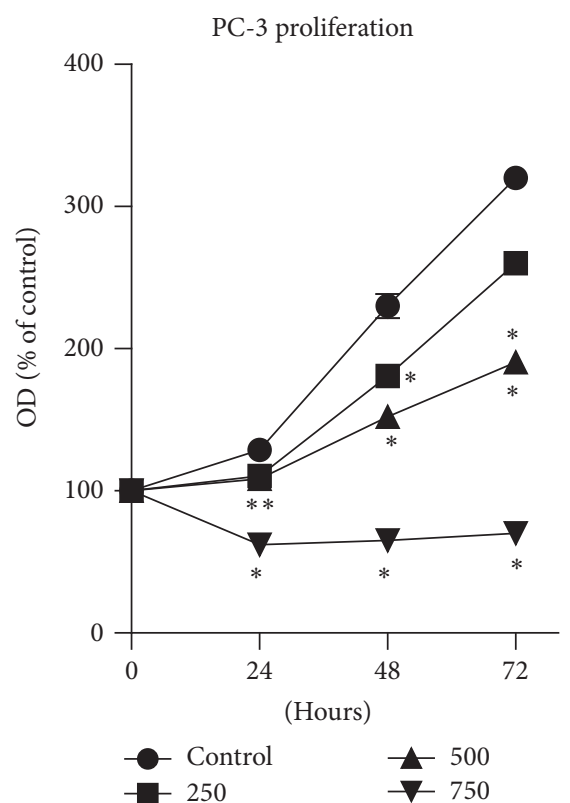

(b)

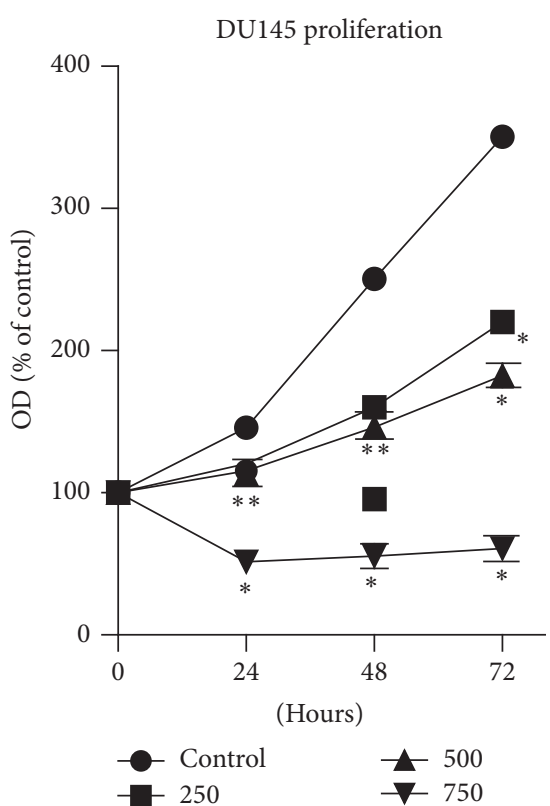

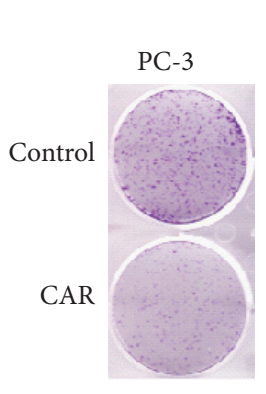

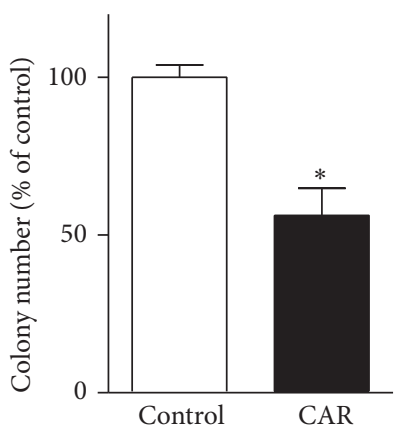

(c)
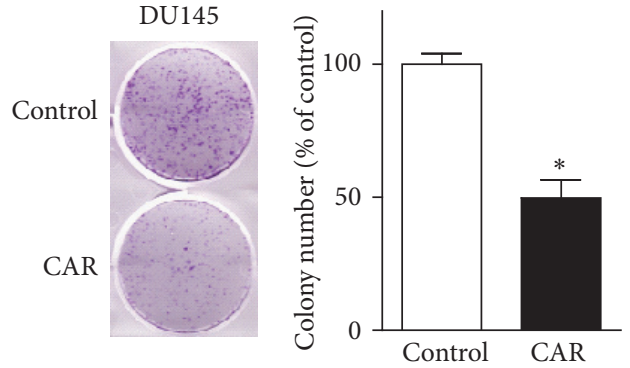

(d)

Figure 2: Carvacrol reduced PCa cell proliferation. (a) PC-3 and DU145 cells were treated with 125 1000 $\mu$ M for 24 h, then CCK-8 assay was conducted, and $\mathrm{IC}_{50}$ was calculated through nonlinear regression fitting $(n=6) . \mathrm{IC}_{50}$ in PC-3 and DU145 cells were $498.3 \pm 12.2 \mu \mathrm{M}$ and $430.6 \pm 21.9 \mu \mathrm{M}$, respectively. OD is the abbreviation of optical density. (b) PC-3 cells (the left panel) and DU145 cells (the right panel) were treated with either vehicle control or carvacrol with 250,500 , and $750 \mu \mathrm{M}$ for 24,48 , and 72 hours, respectively. Then cell proliferation curves were detected by CCK- 8 assay $\left({ }^{*} p<0.05\right.$ versus control, $\left.n=6\right)$. (c) Carvacrol reduced colony formation of PC-3 cells $\left({ }^{*} p<0.05, n=6\right)$. (d) Carvacrol reduced colony formation of DU145 cells $\left({ }^{*} p<0.05, n=6\right)$. ** refers to the comparisons of carvacrol at 250 and $500 \mu \mathrm{M}$, respectively.

the results indicated that carvacrol $(500 \mu \mathrm{M})$ treatment significantly reduced PC-3 and DU145 cell invasion to $22.3 \pm$ $7.2 \%$ and $18.9 \pm 5.8 \%$ versus vehicle control, respectively $(p<0.05, n=6)$. High expression level of MMP-2 suggests the strong ability of invasion. Thus, we determined MMP2 expression using western blotting. As shown in Figures $4\left(a^{\prime}\right)$ and $4\left(b^{\prime}\right)$, western blotting results showed that carvacrol $(500 \mu \mathrm{M})$ treatment significantly reduced MMP-2 protein expression in both PC-3 and DU145 cells ( $p<0.05, n=6)$.

3.5. Carvacrol Suppresses PI3K/Akt and MAPK Signaling Pathways. Next, we studied the underlying signaling pathway involved in the anti-PCa effects of carvacrol. As shown in Figure 5, in carvacrol treatment group, phosphorylation of p-Akt and p-ERK in PC-3 cells was significantly reduced to
$21.2 \pm 4.5 \%$ and $36.4 \pm 7.9 \%$ of vehicle control $(p<0.06, n=$ $6)$. In the meantime, similar results were observed in DU145 cells. The data suggest that PI3K/Akt and MAPK signaling pathways are involved in anti-PCa effects of carvacrol.

3.6. TRPM7 Knockdown Regulates the Functions of Prostate Cancer Cells. As shown in Figure 6(a), PC-3 cells infected with lentivirus vector with shRNA-TRPM7 for $72 \mathrm{~h}$ significantly decreased TRPM7 protein expression, comparing with shRNA-Control ( $p<0.05, n=4)$. Moreover, TRPM7 knockdown significantly reduced TRPM7-like current as well $(p<0.05$, Figures 6(b) and 6(c)), whereas carvacrol did not further significantly reduce TRPM7-like currents in TRPM7 knockdown PC-3 cells (Figure 6(b)). TRPM7 knockdown significantly inhibited PC-3 cell proliferation (Figure 6(d)), 

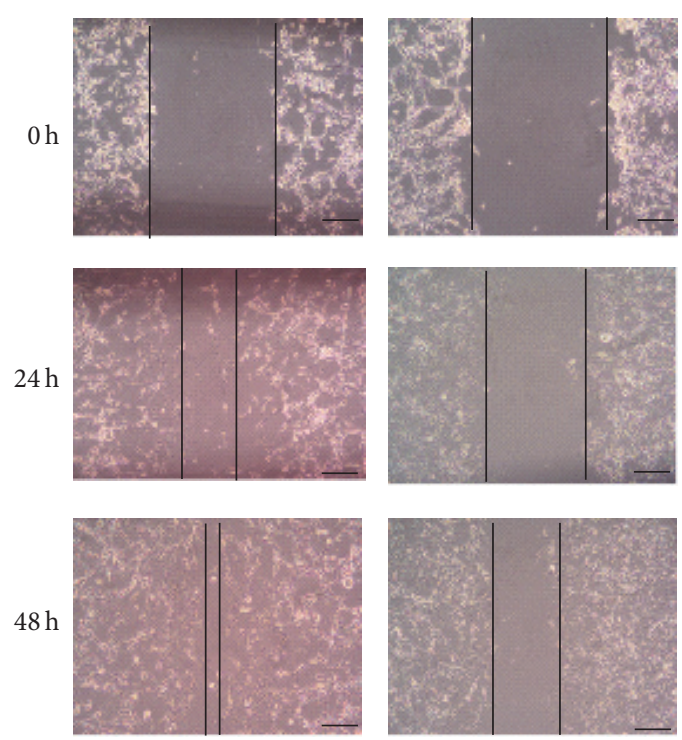

Control
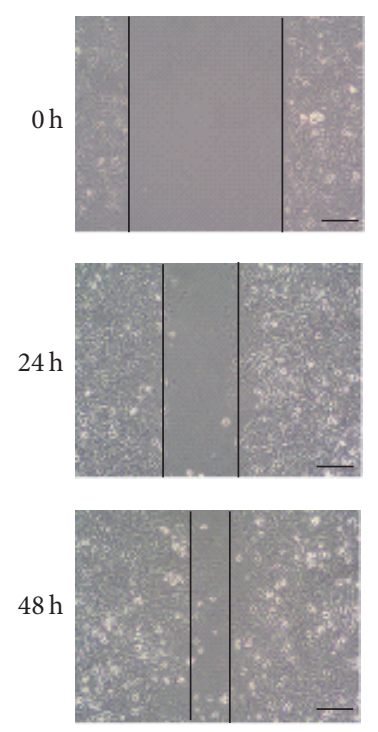

Control
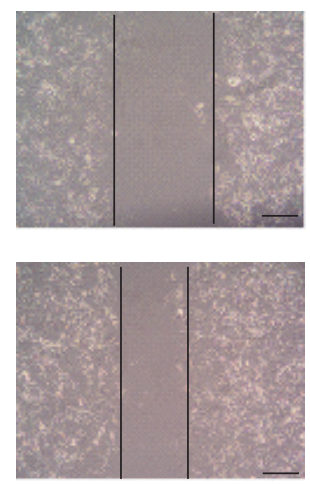

CAR
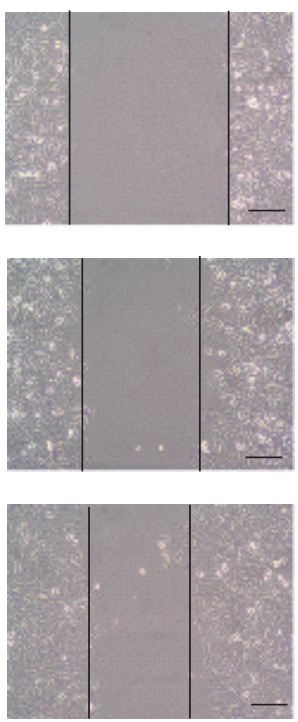

CAR

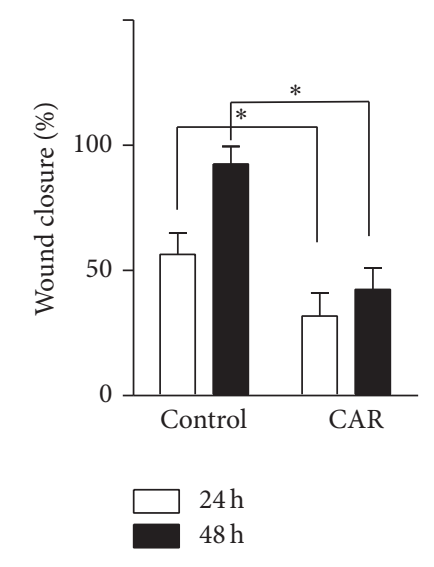

(a)

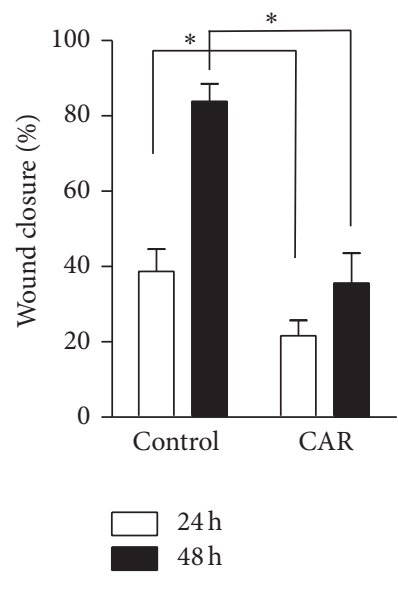

(b)

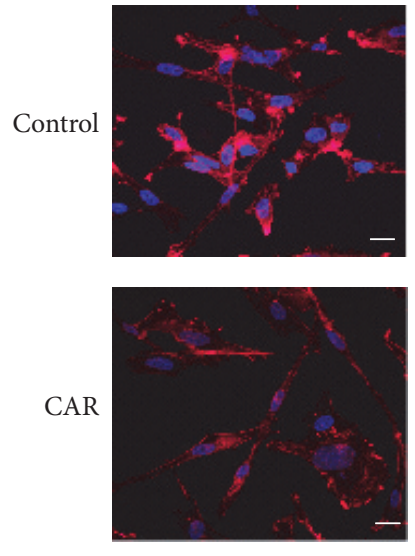

$\left(a^{\prime}\right)$

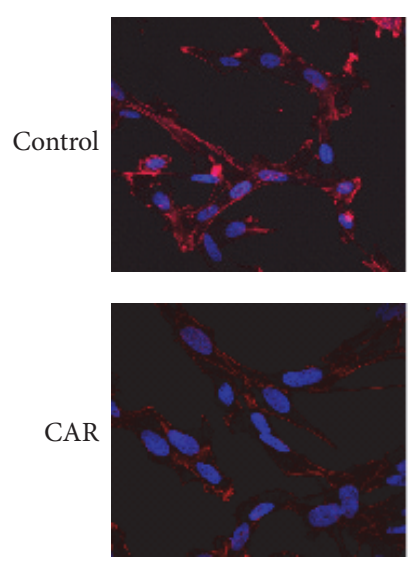

$\left(b^{\prime}\right)$

Figure 3: Carvacrol inhibited PCa cell migration. (a) PC-3 cells were treated with carvacrol (500 $\mu \mathrm{M})$ for 24 and $48 \mathrm{~h}$. Images were taken at indicated time points. Wound closure was compared between vehicle control and carvacrol treated group $\left({ }^{*} p<0.05, n=6\right)$. $\left(\mathrm{a}^{\prime}\right)$ Representative images of F-actin staining in PC-3 were showed $(n=6)$. (b) Wound healing assay and closure analysis were carried out as described in PC-3 cells $\left({ }^{*} p<0.05, n=6\right)$. ( $\left.\mathrm{b}^{\prime}\right)$ Representative images of F-actin staining in DU145 cells were showed $(n=6)$.

migration (Figures 6(e) and 6(f)), and invasion (Figure 6(g)). The protein levels of p-Akt and p-ERK1/2 were reduced by TRPM7 knockdown as well (Figure 6(h)).

\section{Discussion}

In the present study, we demonstrated that carvacrol inhibited TRPM7-like currents in PCa cells and reduced cell proliferation, migration, and invasion of PCa cell. Furthermore, we found that carvacrol treatment decreased MMP-2, p-Akt, and
p-ERK protein expression and blocked F-actin reorganization in PCa cells. Consistently, TRPM7 knockdown inhibited PC-3 cell proliferation, migration, and invasion. It also suppressed p-Akt and p-ERK protein expression in PC-3 cells as well. TRPM7 channels are widely expressed in a variety of cells including prostate tissues [28]. Activation of TRPM7 promotes prostate cancer cell proliferation, migration, and viability $[10,11]$, while inhibition of TRPM7 by $\mathrm{Gd}^{3+}$ or 2-aminoethoxy diphenylborate (2-APB) enhances TRAILinduced PC-3 cell apoptosis [12]. Carvacrol, an approved food 

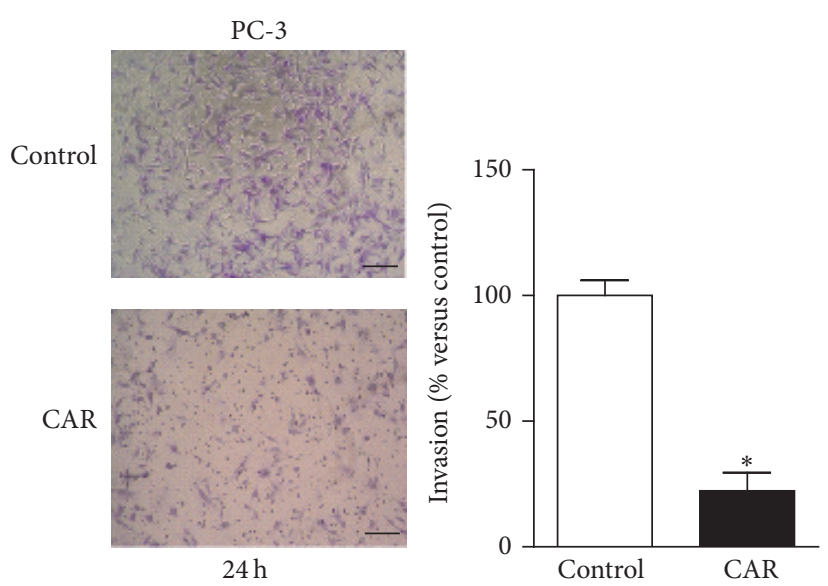

(a)
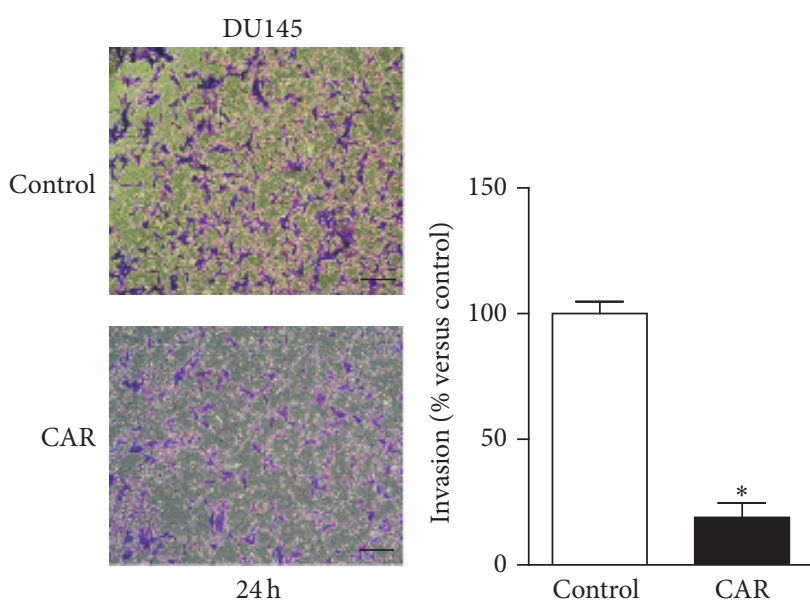

(b)

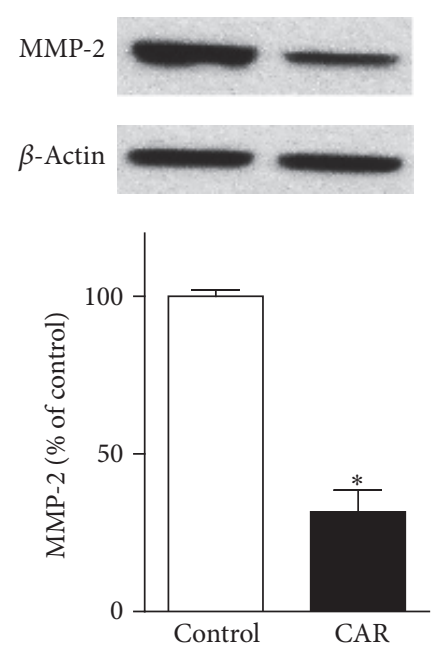

$\left(a^{\prime}\right)$
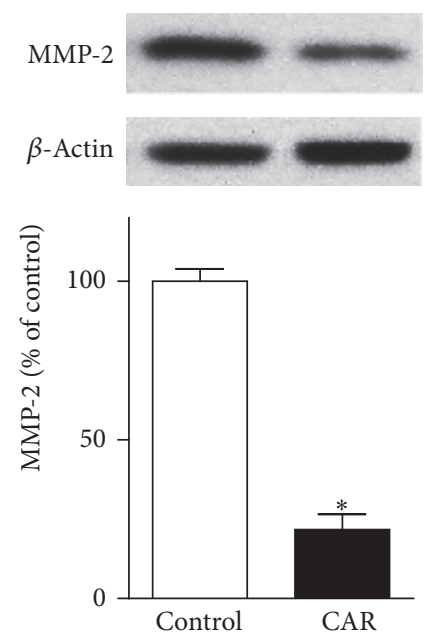

$\left(\mathrm{b}^{\prime}\right)$

FIGURE 4: Carvacrol inhibited PCa cell invasion. (a) Representative images of Transwell assay in PC-3 cells were showed. Carvacrol treatment significantly reduced the invasion of PC-3 cells $\left({ }^{*} p<0.05, n=6\right)$. $\left(\mathrm{a}^{\prime}\right)$ Western blot showed that carvacrol treatment for $24 \mathrm{~h}$ reduced MMP2 protein expression in PC-3 cells $\left({ }^{*} p<0.05, n=6\right)$. (b) Representative images of Transwell assay in DU145 cells were showed. Carvacrol treatment significantly reduced the invasion of DU145 cells $\left({ }^{*} p<0.05, n=6\right)$. ( $\left.\mathrm{b}^{\prime}\right)$ Western blot showed that carvacrol treatment for $24 \mathrm{~h}$ reduced MMP-2 protein expression in DU145 cells $\left({ }^{*} p<0.05, n=6\right)$.

flavor additive by the United States Food and Drug Administration (FDA), with oral $\mathrm{LD}_{50}$ is $810 \mathrm{mg} / \mathrm{kg}$ in rats [29] which was reported as a nonspecific TRPM7 inhibitor with $\mathrm{IC}_{50}$ of $306 \pm 65 \mu \mathrm{M}$ [17]. Our data showed the inhibitory effects of carvacrol on TRPM7-like currents in PC-3 and DU145 cells, which was consistent with another researcher's study [7]. Furthermore, our results showed that both carvacrol treatment and TRPM7 knockdown significantly suppressed cell proliferation, migration, and invasion of PCa cells. These results suggest that blocking TRPM7 by carvacrol plays a key role in PCa growth and metastasis.

Cell adhesion and spreading properties directly regulate the cellular motility and invasiveness. F-actin dynamics is essential for alteration of cytoskeleton during cell migration and invasion [30]. We found that carvacrol treatment inhibited F-actin condensing at the leading edge of PCa cells, indicating that carvacrol reduced PCa cell motility through blocking F-actin-mediated cytoskeleton alteration. Matrix metalloproteinase-2 (MMP-2) is essential for focal extracellular matrix (ECM) degradation and invasion of the surrounding tissue. MMP-2 expression decreased in glioblastoma cells by treatment with carvacrol [7]. Consistently, we also found that carvacrol reduced MMP-2 protein expression in both PC-3 and DU145 cells. Hence, we could speculate that suppression of PCa functions by carvacrol might be closely related to regulation of F-actin and MMP-2 expression.

PI3K/Akt and MAPK signaling pathways are important in the PCa growth and metastasis [31,32]. Phosphorylation of Akt and ERK is the key proteins regulating both signaling pathways, respectively. TRPM7 downexpression decreases 

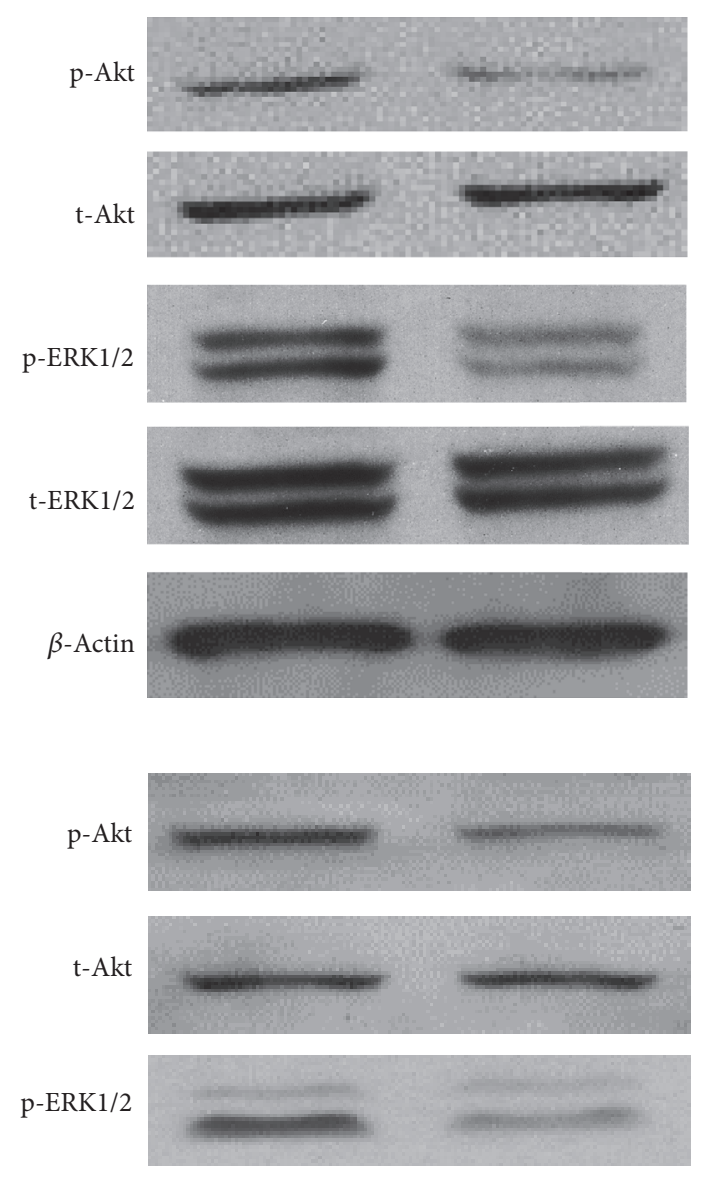

t-ERK1/2

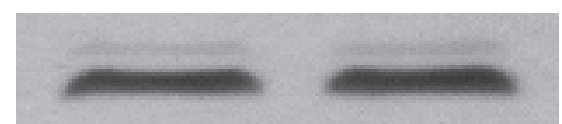

$\beta$-Actin

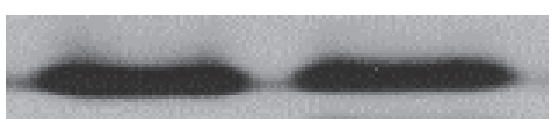

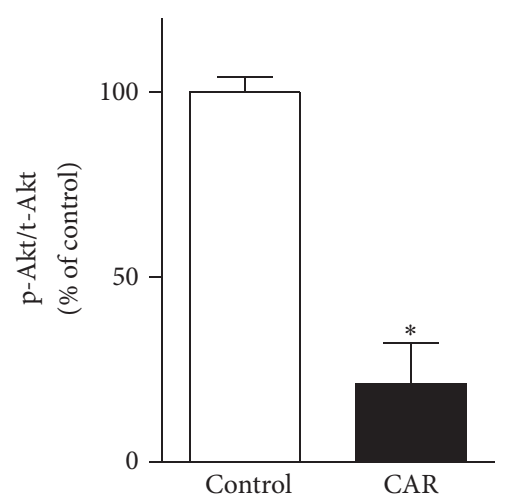

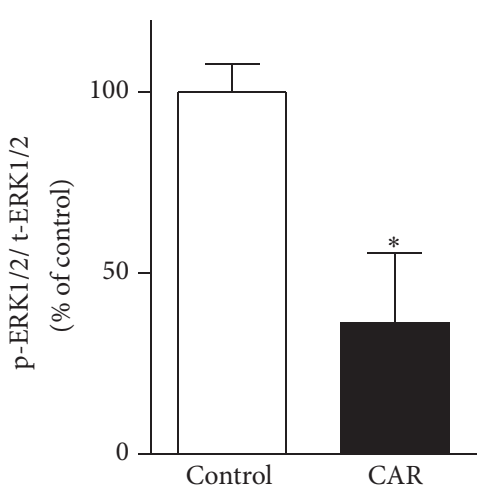

(a)
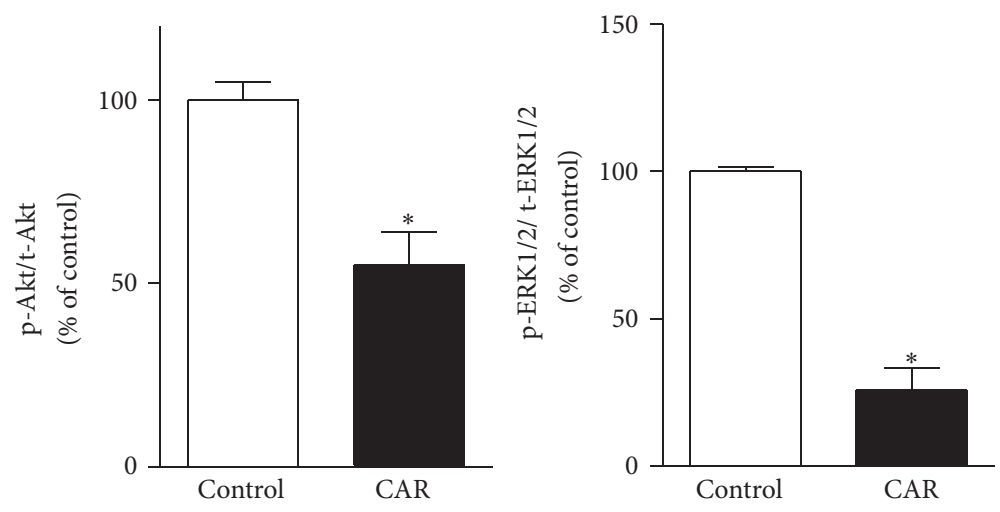

(b)

Figure 5: Carvacrol reduced p-Akt and p-ERK1/2 protein levels in PCa cells. (a) PC-3 cells were treated with carvacrol (500 $\mu \mathrm{M})$ for $24 \mathrm{~h}$, and then western blotting experiments were carried out to detect the indicated protein expression $\left({ }^{*} p<0.05, n=6\right)$. (b) DU145 cells were treated with carvacrol $(500 \mu \mathrm{M})$ for $24 \mathrm{~h}$, and then western blotting experiments were carried out to detect the indicated protein expression $\left({ }^{*} p<0.05, n=6\right)$.

the phosphorylation of p-Akt in ovarian cancer cells and lung fibroblasts and also decreases the phosphorylation of $\mathrm{p}$ ERK1/2 in breast cancer cells $[8,33,34]$. In this study, our results showed that carvacrol reduced levels of p-Akt and pERK in both PC-3 and DU145 cells, which is consistent with another study [7].

Taken together, carvacrol treatment represses cell proliferation, migration, and invasion in both PC-3 and DU145 PCa cell lines, likely by blocking TRPM7-like current and reducing MMP-2 protein expression and F-actin dynamics. Moreover, both the PI3K/Akt and MEK/MAPK signaling pathways are involved in these antiprostate cancer effects. Our findings indicate that carvacrol has antiprostate cancer effects in vitro.

\section{Competing Interests}

The authors declare that they have no competing interests.

\section{Authors' Contributions}

Yun Luo, Jie-Ying Wu, Ning Na, and Jin-Ming Di contributed equally to this work.

\section{Acknowledgments}

The authors acknowledge the financial support from the Guangdong Natural Science Funds no. 2014A030313180 (JinMing Di), National Natural Science Foundation of China 


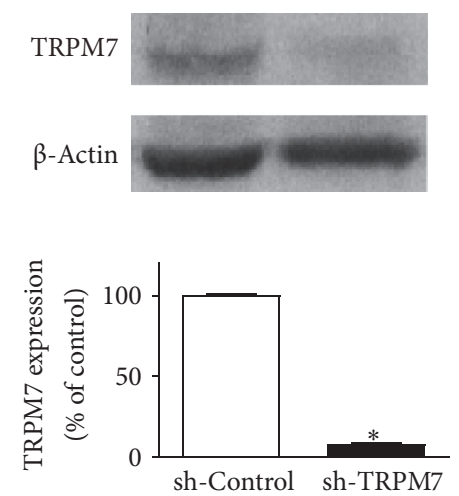

(a)

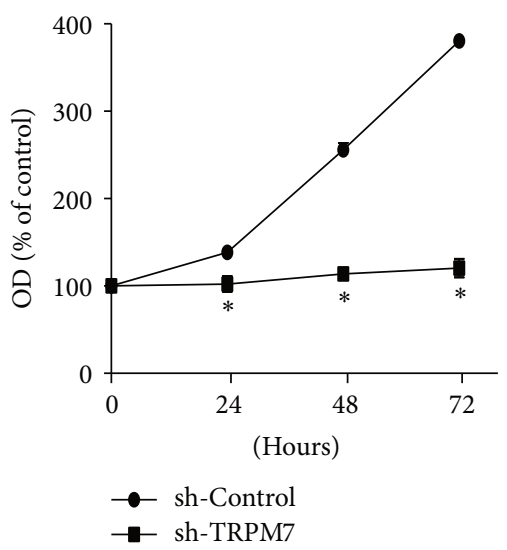

(d)

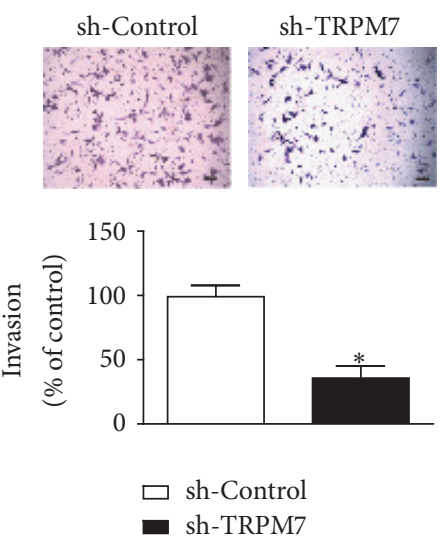

(g)

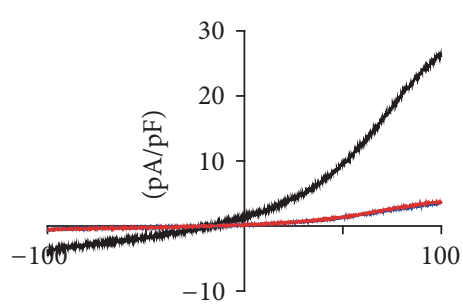

$(\mathrm{mV})$

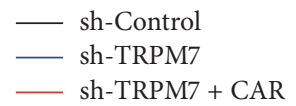

(b)

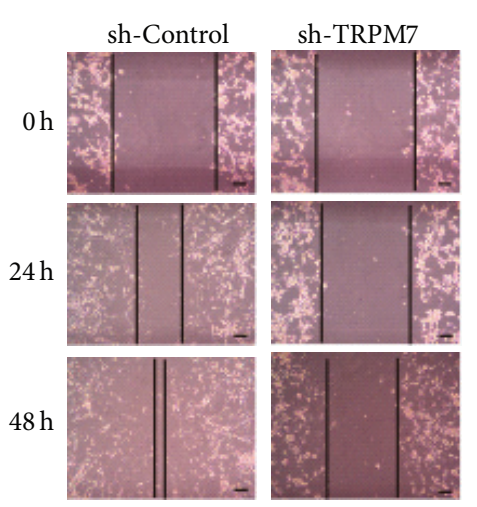

(e)

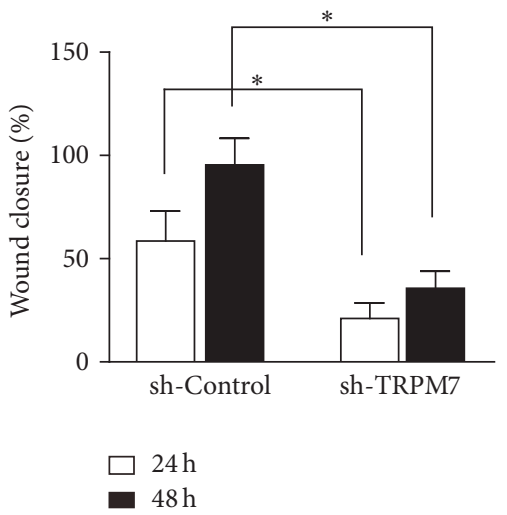

(f)

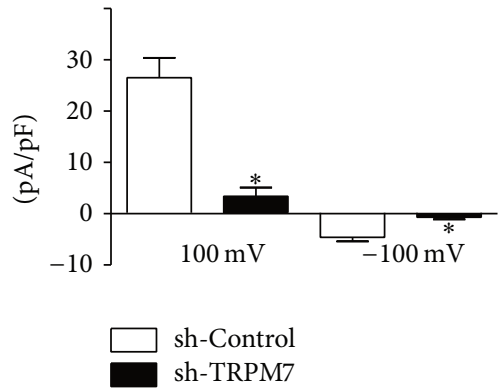

(c)
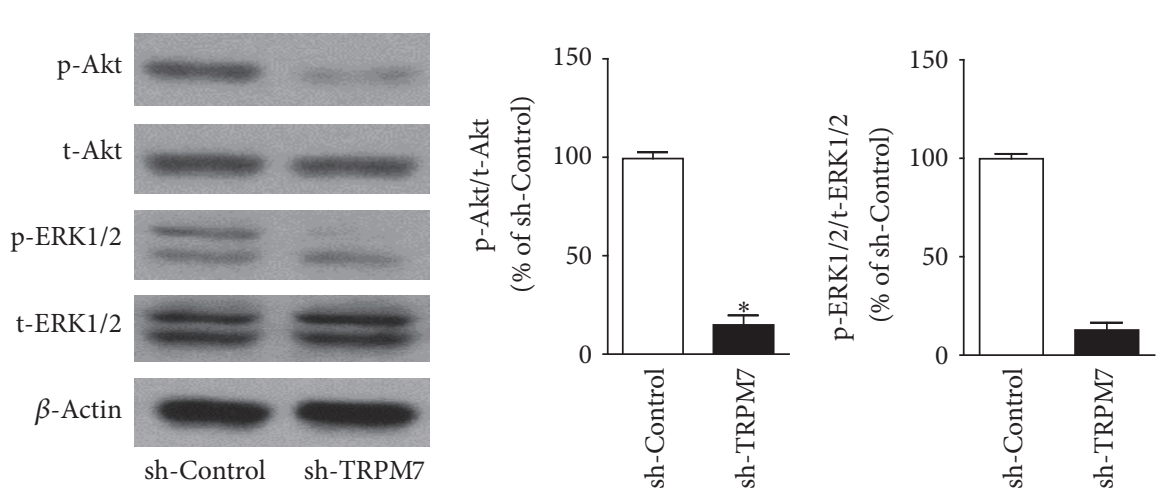

(h)

FIGURE 6: TRPM7 knockdown regulates PC-3 functions. (a) TRPM7 protein expression was determined by western blot after PC-3 infected with lentivirus vector (sh-Control and sh-TRPM7) for $72 \mathrm{~h}\left({ }^{*} p<0.05\right.$ versus sh-Control, $\left.n=4\right)$. (b) After $72 \mathrm{~h}$ infection with either sh-Control or sh-TRPM7 lentivirus, TRPM7-like currents were recorded using patch clamp. Representative $I$ - $V$ traces of PC-3 cells were shown $(n=6)$. (c) Statistical analysis of patch clamp results was shown. TRPM7 knockdown significantly reduced the currents at $+100 \mathrm{mV}$ and $-100 \mathrm{mV}$ $\left({ }^{*} p<0.05, n=6\right)$. (d) TRPM7 knockdown significantly inhibited PC-3 cell proliferation detected by CCK- 8 assay $\left({ }^{*} p<0.05\right.$ versus shControl, $n=6$ ). (e) TRPM7 knockdown significantly inhibited PC-3 cell migration detected by wound healing assay. The representative images were shown $(n=4)$. (f) Statistical analysis of wound healing $\left({ }^{*} p<0.05, n=4\right)$. (g) TRPM7 knockdown significantly inhibited PC-3 cell invasion detected by Transwell assay $\left({ }^{*} p<0.05\right.$ versus sh-Control, $\left.n=4\right)$. (h) TRPM7 knockdown significantly reduced p-Akt and p-ERK1/2 protein levels in PC-3 cells $\left({ }^{*} p<0.05\right.$ versus sh-Control, $\left.n=4\right)$. 
nos. 81201694 (Yun Luo) and 8127083 and 814709775 (Ning $\mathrm{Na}$ ), Specialized Research Fund for the Doctoral Program of Higher Education of China nos. 20120171120059 (Yun Luo) and 2014A020212121 (Ning Na), Science and Technology Planning Project of Guangdong Province no. 2014A020212160 (Yun Luo), Young Teacher Training Program of Sun Yat-sen University no. 15ykpy27 (Yun Luo), and Foundation of the 3rd Affiliated Hospital of Sun Yat-sen University (Yun Luo).

\section{References}

[1] G. Gundem, P. Van Loo, B. Kremeyer et al., "The evolutionary history of lethal metastatic prostate cancer," Nature, vol. 520, no. 7547, pp. 353-357, 2015.

[2] J. M. Di, J. Pang, Q. P. Sun et al., “Toll-like receptor 9 agonists up-regulates the expression of cyclooxygenase-2 via activation of NF- $\kappa \mathrm{B}$ in prostate cancer cells," Molecular Biology Reports, vol. 37, no. 4, pp. 1849-1855, 2010.

[3] J.-M. Di, J. Zhou, X.-L. Zhou et al., "Cyclooxygenase-2 expression is associated with vascular endothelial growth factor- $\mathrm{C}$ and lymph node metastases in human prostate cancer," Archives of Medical Research, vol. 40, no. 4, pp. 268-275, 2009.

[4] A. de la Taille, M. A. Rubin, M.-W. Chen et al., “ $\beta$ Catenin-related anomalies in apoptosis-resistant and hormonerefractory prostate cancer cells," Clinical Cancer Research, vol. 9, no. 5, pp. 1801-1807, 2003.

[5] L. W. Runnels, L. Yue, and D. E. Clapham, "TRP-PLIK, a bifunctional protein with kinase and ion channel activities," Science, vol. 291, no. 5506, pp. 1043-1047, 2001.

[6] L. W. Runnels, "TRPM6 and TRPM7: a Mul-TRP-PLIK-cation of channel functions," Current Pharmaceutical Biotechnology, vol. 12, no. 1, pp. 42-53, 2011.

[7] W.-L. Chen, A. Barszczyk, E. Turlova et al., "Inhibition of TRPM7 by carvacrol suppresses glioblastoma cell proliferation, migration and invasion," Oncotarget, vol. 6, no. 18, pp. 1632116340, 2015.

[8] J. Wang, Q.-J. Liao, Y. Zhang et al., "TRPM7 is required for ovarian cancer cell growth, migration and invasion," Biochemical and Biophysical Research Communications, vol. 454, no. 4, pp. 547-553, 2014.

[9] J. Middelbeek, A. J. Kuipers, L. Henneman et al., "TRPM7 is required for breast tumor cell metastasis," Cancer Research, vol. 72, no. 16, pp. 4250-4261, 2012.

[10] Y. Sun, S. Selvaraj, A. Varma, S. Derry, A. E. Sahmoun, and B. B. Singh, "Increase in serum $\mathrm{Ca} 2+/ \mathrm{Mg} 2+$ ratio promotes proliferation of prostate cancer cells by activating TRPM7 channels," Journal of Biological Chemistry, vol. 288, no. 1, pp. 255-263, 2013.

[11] Y. Sun, P. Sukumaran, A. Varma, S. Derry, A. E. Sahmoun, and B. B. Singh, "Cholesterol-induced activation of TRPM7 regulates cell proliferation, migration, and viability of human prostate cells," Biochimica et Biophysica Acta (BBA)-Molecular Cell Research, vol. 1843, no. 9, pp. 1839-1850, 2014.

[12] C.-M. Lin, J.-M. Ma, L. Zhang et al., "Inhibition of transient receptor potential melastain 7 enhances apoptosis induced by TRAIL in PC-3 cells," Asian Pacific Journal of Cancer Prevention, vol. 16, no. 10, pp. 4469-4475, 2015.

[13] W. Zhou, S. Guo, Z. Xiong, and M. Liu, "Oncogenic role and therapeutic target of transient receptor potential melastatin 7 channel in malignancy," Expert Opinion on Therapeutic Targets, vol. 18, no. 10, pp. 1177-1196, 2014.

[14] M. Liu, K. Inoue, T. Leng, S. Guo, and Z.-G. Xiong, "TRPM7 channels regulate glioma stem cell through STAT3 and Notch signaling pathways," Cellular Signalling, vol. 26, no. 12, pp. 27732781, 2014.

[15] W.-L. Chen, E. Turlova, C. L. F. Sun et al., "Xyloketal B suppresses glioblastoma cell proliferation and migration in vitro through inhibiting TRPM7-regulated PI3K/Akt and MEK/ERK signaling pathways," Marine Drugs, vol. 13, no. 4, pp. 2505-2525, 2015.

[16] Z. E. Suntres, J. Coccimiglio, and M. Alipour, "The bioactivity and toxicological actions of carvacrol," Critical Reviews in Food Science and Nutrition, vol. 55, no. 3, pp. 304-318, 2015.

[17] M. Parnas, M. Peters, D. Dadon et al., "Carvacrol is a novel inhibitor of Drosophila TRPL and mammalian TRPM7 channels," Cell Calcium, vol. 45, no. 3, pp. 300-309, 2009.

[18] J. Du, J. Xie, Z. Zhang et al., “TRPM7-mediated $\mathrm{Ca}^{2+}$ signals confer fibrogenesis in human atrial fibrillation," Circulation Research, vol. 106, no. 5, pp. 992-1003, 2010.

[19] X. L. Mei, Y. Yang, Y. J. Zhang et al., "Sildenafil inhibits the growth of human colorectal cancer in vitro and in vivo," American Journal of Cancer Research, vol. 5, no. 11, pp. 3311-3324, 2015.

[20] Z. Shi, A. K. Tiwari, S. Shukla et al., "Sildenafil reverses ABCB1and ABCG2-mediated chemotherapeutic drug resistance," Cancer Research, vol. 71, no. 8, pp. 3029-3041, 2011.

[21] Y. Luo, Q.-W. Jiang, J.-Y. Wu et al., "Regulation of migration and invasion by Toll-like receptor-9 signaling network in prostate cancer," Oncotarget, vol. 6, no. 26, pp. 22564-22574, 2015.

[22] Y. Luo, J. Y. Wu, G. L. Hou, M. H. Lu, Z. Shi, and J. M. Di, "ODAM is a predictor for biomedical recurrence and inhibits the migration and invasion of prostate cancer," American Journal of Translational Research, vol. 8, no. 2, pp. 670-679, 2016.

[23] J. M. Liu, F. Pan, L. Li et al., "Piperlongumine selectively kills glioblastoma multiforme cells via reactive oxygen species accumulation dependent JNK and p38 activation," Biochemical and Biophysical Research Communications, vol. 437, no. 1, pp. 8793, 2013.

[24] Z. Shi, H. R. Park, Y. Du et al., "Cablesl complex couples survival signaling to the cell death machinery," Cancer Research, vol. 75, no. 1, pp. 147-158, 2015.

[25] Z. Shi, A. K. Tiwari, S. Shukla et al., "Inhibiting the function of ABCB1 and ABCG2 by the EGFR tyrosine kinase inhibitor AG1478," Biochemical Pharmacology, vol. 77, no. 5, pp. 781-793, 2009.

[26] L.-H. Gong, X.-X. Chen, H. Wang et al., "Piperlongumine induces apoptosis and synergizes with cisplatin or paclitaxel in human ovarian cancer cells," Oxidative Medicine and Cellular Longevity, vol. 2014, Article ID 906804, 10 pages, 2014.

[27] J.-G. Qiu, Y.-J. Zhang, Y. Li et al., “Trametinib modulates cancer multidrug resistance by targeting ABCB1 transporter," Oncotarget, vol. 6, no. 17, pp. 15494-15509, 2015.

[28] H.-P. Wang, X.-Y. Pu, and X.-H. Wang, "Distribution profiles of transient receptor potential melastatin-related and vanilloidrelated channels in prostatic tissue in rat," Asian Journal of Andrology, vol. 9, no. 5, pp. 634-640, 2007.

[29] J. M. Taylor, P. M. Jenner, and W. I. Jones, "A comparison of the toxicity of some allyl, propenyl, and propyl compounds in the rat," Toxicology and Applied Pharmacology, vol. 6, no. 4, pp. 378387, 1964. 
[30] S. K. Martin, M. Kamelgarn, and N. Kyprianou, "Cytoskeleton targeting value in prostate cancer treatment," American Journal of Clinical and Experimental Urology, vol. 2, no. 1, pp. 15-26, 2014.

[31] S. Stelloo, J. Sanders, E. Nevedomskaya et al., "mTOR pathway activation is a favorable prognostic factor in human prostate adenocarcinoma," Oncotarget, vol. 7, no. 22, pp. 32916-32925, 2016.

[32] L. Moro, A. A. Arbini, E. Marra, and M. Greco, "Corrigendum] Constitutive activation of MAPK/ERK inhibits prostate cancer cell proliferation through upregulation of BRCA2," International Journal of Oncology, vol. 48, no. 6, p. 2722, 2016.

[33] M. Yu, C. Huang, Y. Huang, X. Wu, X. Li, and J. Li, "Inhibition of TRPM7 channels prevents proliferation and differentiation of human lung fibroblasts," Inflammation Research, vol. 62, no. 11, pp. 961-970, 2013.

[34] X. Meng, C. Cai, J. Wu et al., "TRPM7 mediates breast cancer cell migration and invasion through the MAPK pathway," Cancer Letters, vol. 333, no. 1, pp. 96-102, 2013. 


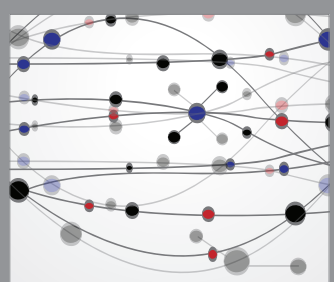

The Scientific World Journal
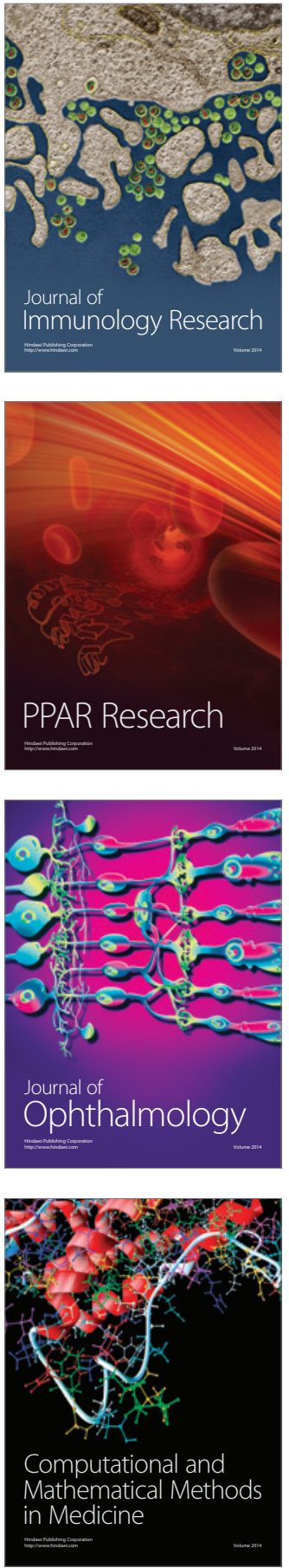

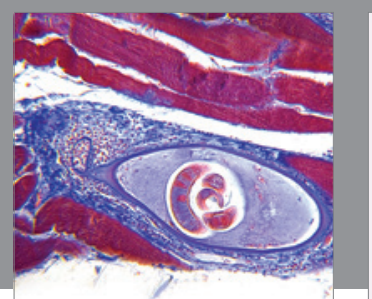

Gastroenterology Research and Practice

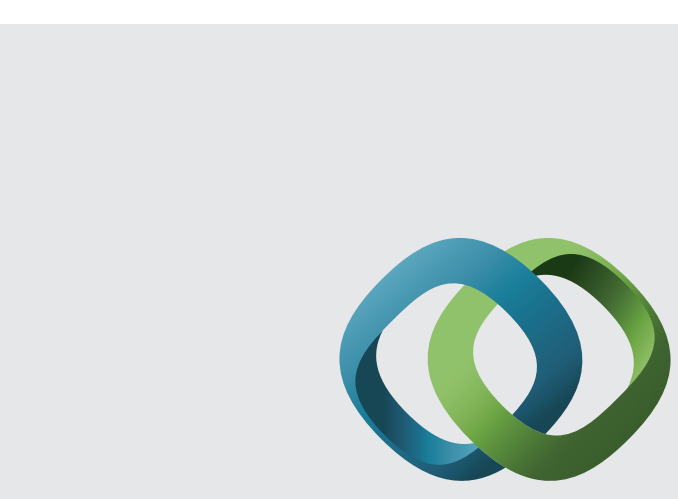

\section{Hindawi}

Submit your manuscripts at

http://www.hindawi.com
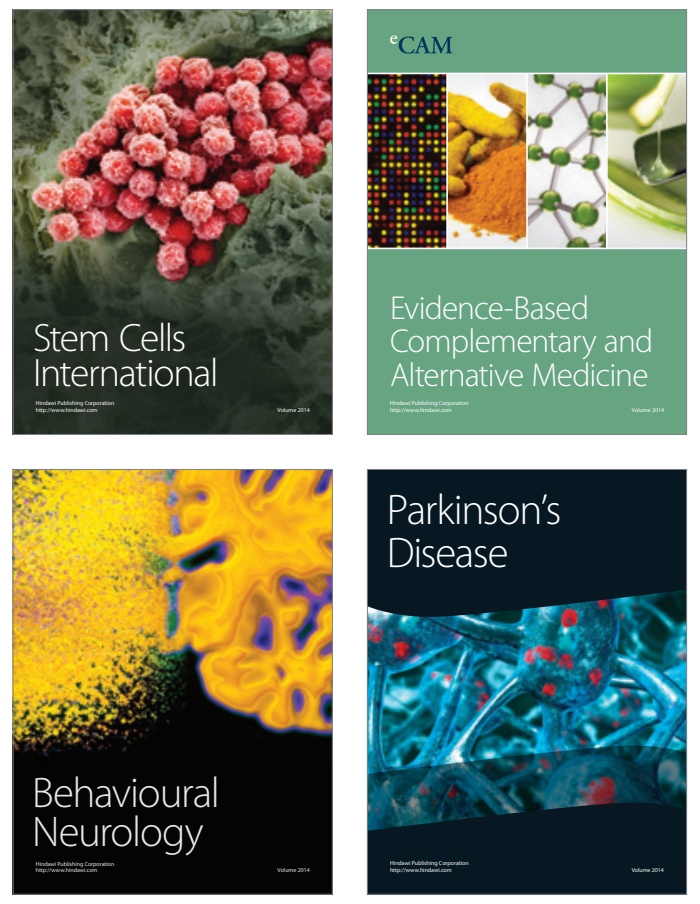
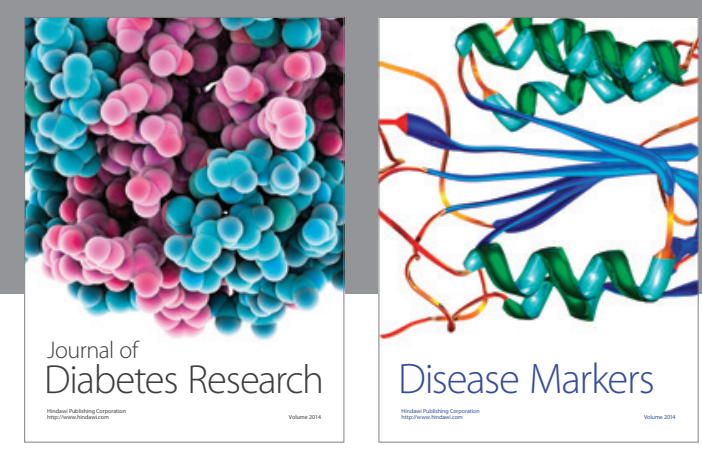

Disease Markers
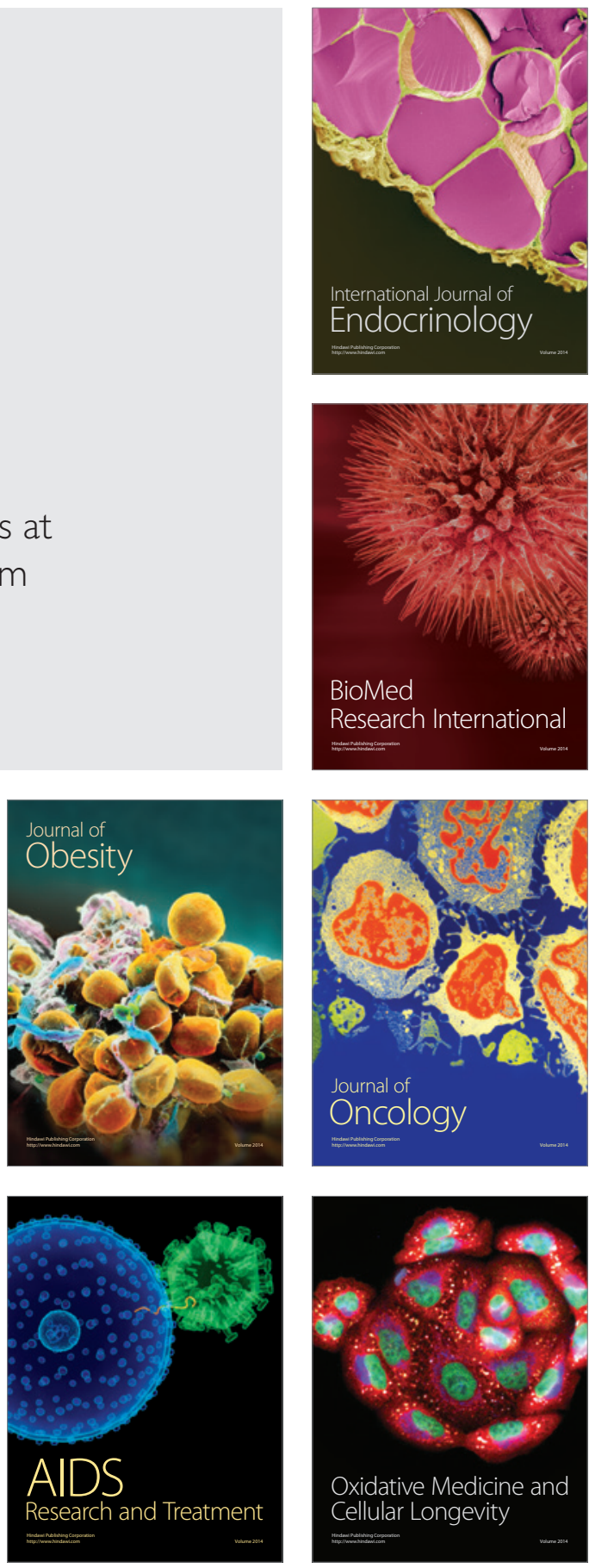